\title{
Media images and popular beliefs
}

\section{Dr Greg Philo of the Glasgow Universtly Media Group summarises some recent research on media portrayals of mental iliness}

In April 1992 the Media Group at Glasgow University began a study of media representations of mental health and illness funded by the Health Education Board for Scotland. The research had two strands: a survey and content analysis of media coverage, and a simultaneous study of audience reception processes. The content sample focused on television news and press reporting plus popular magazines and children's literature as well as fictional TV, such as soap operas, films and drama. This yielded a total of 562 items whose content fell into five main categories: violence to others, harm to self, sympathetic coverage, criticism of accepted definitions of mental illness and 'comic' images. As an example of the last category, the Ruby Wax show offered a 'comic' presentation of the rehabilitation of Joanna Lumley:

Wax: We have someone here with us tonight who recently joined the ranks of the chronically barking . . . I know you are going to be kind because if you are not she may pull a knife . . back from the abyss, Miss Joanna Lumley! (BBC, 22 April 1992).

Overall in the coverage, the category of 'violence to others' was by far the most common, outweighing the next most common, 'sympathetic', by a ratio of almost four to one. We also found that items linking mental illness and violence tended to receive 'headline' treatment, while sympathetic items were largely 'back page' in their profile, such as problem page letters or health columns.

The audience reception study used 70 people divided into focus groups, who were asked to work through a programme of exercises and interviews. In the exercises, sub-groups of two or three people were asked to write news reports prompted by coples of original headlines from newspapers. They were also asked to write dialogue for an episode of ITV's Coronation Street prompted by still photographs from the programme. Following this, each member of the group gave written replies to questions. In writing their own stories, the audience groups demonstrated a remarkable ability to reproduce the style and language of television news and the press. We also found that some group members could reproduce detailed and accurate scripts

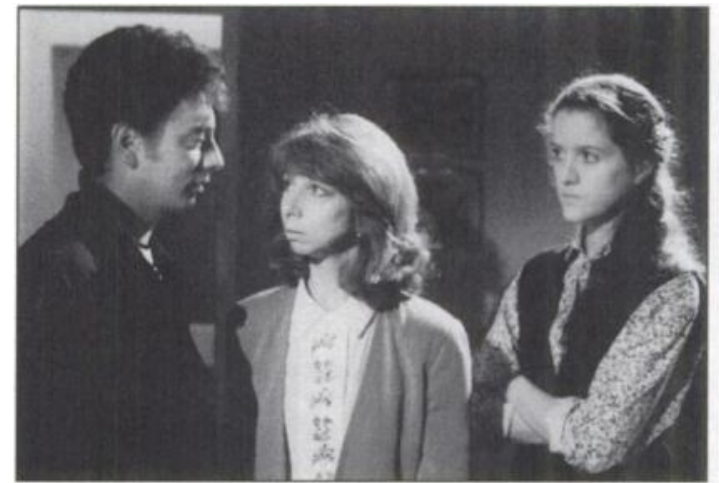

Sean Wilson as Martin, Helen Worth as Gail (his wife) and Catherine Cusack as Carmel in 'Coronation Street'. Copyright Granada IV.

from Coronation Street, months after the relevant scenes had been transmitted. The photographs which they used related to a story line in which a mentally ill person had an erotic fixation for the husband of one of the regular characters. These scenes had apparently generated an intense hostility towards the mentally ill character among the majority of the group members who had seen them. We asked how they would have reacted to her and received many responses such as "killed her". "battered her bloody mouth in". "kicked hell out of her" and "I would have killed the cow". A much smaller number suggested that she needed psychiatric help - a judgement which was made mostly on the basis of their own professional or personal experience in the area. But even here, the judgement could be accompanied by a list of other things which had to be 'done' to the woman first:

"(I would have) thrown her out of the house, denounced her in public and with Martin (the husband) by my side, let the whole world know what she was up to. Then suggested to her that she needed psychiatric help."

Media presentations were also a very powerful influence on beliefs about the nature of mental Illness. For example, the character Trevor Jordache in the soap opera Brookside was presented as alternating between being an amiable loving family man and making violent threats to his wife: "you won't tell anyone, because if you do I'll kill you, do you understand?" (17 April 1993). 
In the popular press, he was referred to as "psycho Trevor" (Daily Star, 19 April 1993) and in our group interviews, he was spontaneously referred to as being "what a mentally ill person was like". As one female interviewee commented:

"... in Brookside, that man who is the childabuser and the wife-beater, he looks like a schizophrenic - he's like a split personality. like two different people."

One of the key issues explored in this research was whether serious mental illness was believed to be associated with violence. Forty per cent of the people in the general sample believed this to be so, while giving the media as the source of their beliefs. The depth of anxiety is so great in this area, that some media accounts can apparently exert great power. In other research programmes, we have studied many different areas of media content. We have normally found that personal experience is a much stronger influence on belief than the messages which are given by media. But in this research we found cases where this pattern was reversed.

We found a number of cases $(21 \%$ of the general sample) where people had non-violent experience which was apparently 'overlaid' by media influences. These people traced their beliefs mostly to violent portrayals in fiction or to news reporting. A further example of this was given by a young woman who lived near Woodilee Hospital just outside Glasgow. She wrote that she had worked there at a jumble sale and mixed with patients. Yet she associated mental illness with violence and wrote of "split/double personalities, one side violent". She then went on to say:

"The actual people I met weren't violent - that I think they are violent, that comes from television. from plays and things. That's the strange thing the people were mainly geriatric - it wasn't the people you hear of on television. Not all of them were old. some of them were younger. None of them were violent - but I remember being scared of them, because it was a mental hospital - it's not a very good attitude to have but it is the way things come across on TV, and films - you know, mental axe murders and plays and things - the people I met weren't like that, but that is what I associated them with".

We also found clear links between media representations and public attitudes to policies such as community care. An interviewee related her own beliefs about violence and mental illness to "Hollywood film and television drama". She then commented that "I feel that government policies in Britain of putting mentally ill people in the "care of the community', is dangerous".

Another area of crucial importance is how media images may affect the beliefs and selfdefinitions of users of the mental health service. and the responses of their families and other carers. For example, if the association of schizophrenia with violence is so widespread in popular belief, then what does this say to the families of people with such an illness? There are very few 'positive' images in the media in the sense that people can recover, achieve or be active in their own right. This is an area which we intend to research further and on which mental health professionals might wish to focus. If it is thought that media representations can be harmful to patients then it is perhaps time to draw this very forcibly to the attention of journalists, broadcasters and all those in the communications industry who make the images.

Greg Philo, Research Director, Glasgow University Media Unit, 61 South Park Avenue, Glasgow G12 8LF

\section{Corrigendum}

In the article 'Otto Dix: Appearance and the Unconscious' by Ismond Rosen (Psychiatric Bulletin, 1993, 17, 727-732), the first sentence should have read: "Otto Dix (1891-1969) was a leading German Expressionist painter whose major work was associated with the Weimar Republic period, although his art extended from before to after both world wars". 